\title{
PREVALENCE, CHARACTERISTICS, AND WORK-RELATED RISK FACTORS OF LOW BACK PAIN AMONG HOSPITAL NURSES IN TAIWAN: A CROSS-SECTIONAL SURVEY
}

\author{
PEI-HSIN LIN ${ }^{1,2}$, YUN-AN TSAI ${ }^{1,2}$, WEI-CHIH CHEN ${ }^{3}$, and SHIH-FONG HUANG ${ }^{1,2}$ \\ ${ }^{1}$ Neurological Institute, Taipei Veterans General Hospital, Taipei, Taiwan, Republic of China \\ Division of Neural Repair \\ ${ }^{2}$ National Yang-Ming University, Taipei, Taiwan, Republic of China \\ School of Medicine, \\ ${ }^{3}$ Department of Health, Executive Yuan, Taipei, Keelung City, Taiwan, Republic of China \\ Department of Physical Medicine and Rehabilitation
}

\begin{abstract}
Background: Low back pain is a common health problem among hospital nurses. However, the prevalence, characteristics, and work-related risk factors of low back pain have not been widely investigated in Taiwan. Materials and Methods: This study used a cross-sectional survey of 217 hospital nurses to gather self-reported information on the prevalence of back pain, demographic and pain characteristics, and work-related risk factors from 178 respondents who indicated a past history of back pain. The association between the characteristics of back pain and work-related risk factors was also examined. Results: The lifetime prevalence of back pain was $82.03 \%$, and the point prevalence of back pain was $43.78 \%$. The mean pain score is 41.67. The number of years at work was significantly associated with the pain score for an individual's most recent episode of back pain, the extent of bothersomeness of back pain and leg pain, and the extent to which back pain interfered with normal work. Conclusion: Back pain is common among hospital nurses in Taiwan. Years at work are significantly associated with pain severity and disability caused by back pain.
\end{abstract}

Key words:

Low back pain, Nurses, Prevalence, Taiwan

\section{INTRODUCTION}

Low back pain is common in the general population worldwide. Epidemiologic studies have demonstrated that: (1) the lifetime prevalence of low back pain ranges from $70 \%$ to $85 \%$, (2) the annual prevalence ranges from $15 \%$ to $45 \%$, and (3) the point prevalence is approximately $30 \%$ [1]. Low back pain is a common cause of work-related injury and disability. According to the National Institute for Occupational Safety and Health, back injury is one of the most common occupational injuries in the United States [2]. Occupational low back injury, leading to long-term pain and disability, results in substantial medical expenses as well as the loss of remuneration for work.

Received: July 17, 2011. Accepted: August 30, 2011.

Address reprint request to Dr. Shih-Fong Huang, Division of Neural Repair, Neurological Institute, Taipei Veterans General Hospital, 201 Section 2, Shih-Pai Road, Taipei, Taiwan R.O.C. 11217 (e-mail: sfhuang7@vghtpe.gov.tw). 
Nurses have the highest prevalence of low back pain among all health care personnel [3,4]. Of all the occupations in which workers make compensation claims for back problems, nurses have the highest incidence rate of this condition [5]. In a study devoted to nursing staff in long-term care facilities, back injuries accounted for more than a half of the indemnity and medical costs for all injuries incurred in nursing homes and industry wide [6]. Back-related complaints are also among the major predictors of nurses' decisions to leave the nursing profession [7]. Therefore, back pain creates not only a serious burden on the nurses who suffer from it, but also a substantial cost for their hospitals in terms of both lost efficiency and compensation claims for occupational injuries.

A great deal of effort has been devoted to preventing back pain and injuries in nurses. Programs for this purpose have involved physical exercise, equipment provision, lumbar support and stress management. A systematic literature review on the efficacy of such interventions have demonstrated mixed results [1,4]. Conflicting evidence might be due to a lack of high-quality randomized controlled studies, or the multi-factorial character of low back pain in nurses. Numerous factors have been found to increase the risk of back pain for nurses [8]. As cases of back pain that result from different risk factors may respond to different treatment strategies, it is important to understand the work-related risk factors for back pain in nurses.

The prevalence and characteristics of low back pain in nursing personnel have been widely investigated in western countries. On the other hand, studies regarding low back pain in nurses in non-western contexts are sparse. The lack of reliable data on low back pain prevalence in non-western nations prevents the accurate assessment of the impact of low back pain in the general population of these countries. Accurate low back pain prevalence estimates can serve as a basis for better etiologic studies and evaluation of health care. By understanding workrelated factors in back pain, one can also identify the causes of back pain in nurses and develop appropriate treatment strategies. The purpose of the present study is to investigate the work-related factors, and their prevalence, in low back pain in Taiwanese nurses through a cross-sectional survey.

\section{MATERIALS AND METHODS}

\section{Study population}

The study population consisted of 217 nurses employed by Keelung Hospital, a 650-bed teaching facility affiliated with the Department of Health of the Taiwanese government that employs approximately 100 full-time medical doctors in more than 30 clinical specialties. All full-time registered nurses, except those working in the operating room, were included in this study; nursing students, nursing aids, or part-time nurses were not included.

\section{Study design and data collection}

This study involved a cross-sectional survey based on a self-administered questionnaire. The questionnaire was distributed from January 1, 2007 to March 31, 2007 to all full-time registered nurses employed by Keelung Hospital. The questionnaire collected self-reported information including demographic and work-related characteristics, current or previous history of low back pain, characteristics of back pain, and disability caused by back pain. Finally, respondents were asked whether they were willing to attend a complimentary exercise class to help them prevent or alleviate their back problems. The Institutional Review Board of Keelung Hospital approved the study.

\section{Measures}

\section{Demographic and work-related characteristics}

Demographic characteristics of interest in this study included age and gender. Work-related characteristics 
included both the number of years the participants worked as a nurse and the units in which the nurses worked in the hospital. With regard to the units in which the nurses worked, the respondents were divided into two groups: nurses performing clinical tasks and nurses performing administrative tasks. Nurses who worked in wards, intensive units, or the hemo-dialysis room were classified as "doing clinical tasks", while nurses who worked in the outpatient department, the pulmonary function examination room, the admission service center, the transfer service center, or the health education room were classified as "doing administrative tasks".

\section{History of back pain and pain characteristics}

Respondents were asked to report whether they had a current or previous history of back pain or sciaticarelated leg pain. Those who reported a previous history of back pain were asked to indicate the severity and duration of the most recent episode of back pain. The severity of back pain was graded using the visual analogue scale (VAS), on which scores range from 0 to 100 . The duration of back pain was treated as an ordinal variable and categorized into five groups: less than 7 days, 7 days to less than 3 months, 3 months to less than 6 months, and 6 months and over.

\section{Outcome of back pain}

\section{(Standardized Core Set Questionnaire)}

For those who reported a past history of low back pain or sciatica-related leg pain, this study used the six-item standardized Core Set questionnaire to collect information regarding the outcome of back pain. The parsimonious six-item Core Set was proposed by an international program on primary care research on back pain in 1997 to include the following dimensions of the outcomes of low back pain: symptoms, function, general well-being, work disability and satisfaction with care. The Core Set was recommended for use in routine clinical care, quality control, and research studies for low back pain [9]. The traditional Chinese version of the Core Set questionnaire used in this study was translated by Lee et al. in 2006 [10].

\section{Data analysis}

Data analysis was conducted using Small Stata 11.0 for Mac (College Station, TX). We analyzed the factors associated with pain characteristics, the Six-Item Core Set, and the willingness to attend a complimentary exercise program. An analysis of linear outcome variables such as age, number of years at work, and VAS was performed using the linear regression technique. An analysis of binary outcome variables such as whether respondents performed administrative tasks at work (vs. clinical tasks at work) was conducted using the logistic regression technique. An analysis of ordinal outcome variables such as the duration of the most recent episode of back pain was performed using the ordinal logistic regression technique.

\section{RESULTS}

\section{Demographic characteristics}

A total of 217 participants completed and returned the questionnaire, for a response rate: $217 / 292=74.3 \%$. The total number of full-time registered nurses at Keelung Hospital during the study period was 319 . Our survey excluded 19 nurses from the operating room and 8 from the anesthesiology section, thereby including 292 nurses. The demographic and baseline characteristics of the respondents are presented in Table 1. Although the survey did not exclude male employees, all full-time registered nurses at the Keelung Hospital during the period from January 2007 to March 2007 were female; therefore, all of the respondents were female. The mean age of the respondents was 31.2 (with respondents' ages ranging from 21 to 59 years). Among the participants, the average amount of time worked as a nurse was 7.3 years (with nurses' time at work ranging from 0.25 to 32 years). 
Table 1. Characteristics of the study population

\begin{tabular}{lc}
\hline \multicolumn{1}{c}{ Characteristics } & $\begin{array}{c}\text { Respondents } \\
\text { [number/total* }(\%)]\end{array}$ \\
\hline $\begin{array}{l}\text { Demographic characteristics } \\
\text { age, mean } \pm \mathrm{SD}^{* *} \text { (range) }\end{array}$ & $31.20 \pm 25.35(21 \sim 59)$ \\
Pain characteristics & \\
having had back pain, lifetime prevalence & $178 / 217(82.03)$ \\
having back pain now, point prevalence & $94 / 216(43.52)$ \\
Duration of the most recent episode of back pain & \\
less than 7 days & $122 / 178(68.54)$ \\
7 days to less than 1 month & $22 / 178(12.36)$ \\
1 to less than 3 months & $7 / 178(3.93)$ \\
3 to less than 6 months & $6 / 178(3.37)$ \\
6 months and over & $21 / 178(11.80)$ \\
Visual analogue scale of the most recent episode of back pain, mean \pm SD $^{* *}($ range $)$ & $41.62 \pm 21.71(0 \sim 100)$ \\
Work-related characteristics & \\
years at work, mean $\pm S D^{* *}$ (range) & $7.31 \pm 6.77(0.25 \sim 32)$ \\
doing administrative tasks at work & $65 / 217(29.95)$ \\
\hline
\end{tabular}

* The total number of respondents varies across items because respondents did not respond to all items.

**SD - standard deviation.

\section{Prevalence of back pain}

Among the 217 respondents, 178 nurses reported to have a previous history of low back pain (the lifetime prevalence $=82.03 \%$ ). The point prevalence of low back pain (i.e., percentage of respondents who reported current pain) was $94 / 216=43.52 \%$.

\section{Pain characteristics}

The pain characteristics of the respondents who reported a past history of pain are shown in Table 1. Among the 178 nurses who reported a previous history of back pain, most respondents $(68.54 \%$ ) reported that the duration of back pain lasted less than 7 days. The mean pain score represented by the visual analogue scale was 41.67 (with a range from 0 to 100). Only 40 respondents $(22.5 \%)$ were willing to take part in a complimentary back exercise program.

\section{Functional profile of back pain: Six-item core set}

Table 2 contains the results of the Six-Item Core Set for respondents who reported the past history of back pain. Approximately three quarters $(73.21 \%)$ of the respondents reported that low back pain was bothersome, while leg pain (sciatica) was bothersome for more than a half of the respondents $(50.33 \%)$. In addition, $68.79 \%$ of the respondents reported that the experienced pain interfered with their normal work. Approximately half of the respondents $(49.10 \%)$ indicated that they would feel very dissatisfied if they had to spend the rest of their life experiencing the symptoms they had at the time of the study. During the 4 weeks preceding the administration of the questionnaire, the mean number of days the respondents reported that they had to cut down on the things they usually did for more than half of the day because of back pain or leg pain was 0.45 day (with a range from 0 to 7 days), and the mean 
Table 2. Results for the Six-Item Core Set

\section{Questions}

Respondents

[number/total* $(\%)$ ]

1. During the past week, how bothersome was each of the following symptoms?

a. Low back pain

not at all

$45 / 168(26.79)$

slightly bothersome

$85 / 168(50.60)$

moderately bothersome

$32 / 168(19.05)$

very bothersome

$4 / 168(2.38)$

extremely bothersome

$2 / 168(1.19)$

b. Leg pain (sciatica)

not at all

$76 / 153(49.67)$

slightly bothersome

$48 / 153(31.37)$

moderately bothersome

23/153 (15.03)

very bothersome

$2 / 153(1.31)$

extremely bothersome

$4 / 153(2.61)$

2. During the past week, how much did pain interfere with your normal work (including both work

outside the home and house work)?

not at all

$54 / 173(31.21)$

a little bit

$86 / 173(49.71)$

Moderately

$29 / 173(16.76)$

quite a bit

4/173 (2.31)

Extremely

3. If you had to spend the rest of your life with the symptoms you have right now, how would you feel about it?

very dissatisfied

somewhat dissatisfied

neither satisfied nor dissatisfied

$82 / 167(49.10)$

$49 / 167(29.34)$

$34 / 167(20.36)$

somewhat satisfied

$1 / 167(0.60)$

very satisfied

$1 / 167(0.60)$

4. During the past 4 weeks, about how many days did you cut down on the things you usually do for more than half a day because of back pain or leg pain (sciatica)? Mean $\pm \mathrm{SD}^{* *}$ (Range)

5. During the past 4 weeks, how many days did low back pain or leg pain (sciatica) keep you from going to work or school? Mean $\pm \mathrm{SD}^{* *}$ (Range)

$0.45 \pm 1.04(0 \sim 7)$

$\mathrm{n}=155$

$0.17 \pm 0.53(0 \sim 4)$

$\mathrm{n}=155$

6. Over the course of treatment for your low back pain or leg pain (sciatica), how satisfied were you with your overall medical care?

very dissatisfied

$4 / 139(2.88)$

somewhat dissatisfied

$12 / 139(8.63)$

neither satisfied nor dissatisfied

$106 / 139(76.26)$

somewhat satisfied

$14 / 139(10.07)$

very satisfied

$3 / 139(2.16)$

* The total number of respondents varies across items because respondents did not respond to all items.

** SD - standard deviation. 
number of days low back pain or leg pain kept respondents from going to work was 0.17 (range: $0 \sim 4$ days). Finally, 16 respondents $(11.51 \%)$ reported that they were very or somewhat dissatisfied with their overall medical care over the course of the treatment.

\section{Factors associated with pain characteristics}

Table 3 presents information concerning whether age and work-related factors were associated with pain characteristics. The analysis demonstrated that performing administrative tasks at work was significantly associated with a previous history of back pain; age and number of years spent working as a nurse were significantly associated with the severity of the most recent episode of back pain.

\section{Factors associated with outcome of back pain}

Table 4 contains information concerning whether age and work-related factors were associated with the outcome of back pain, as represented by the Six-Item Core Set. The analysis demonstrated that age and the number of years at work as a nurse were significantly associated with the extent of bothersomeness of back pain and the extent to which back pain interfered with normal work.

Table 3. Factors Associated with Pain Characteristics

\begin{tabular}{|c|c|c|c|c|c|c|c|c|}
\hline \multirow{2}{*}{ Factors } & \multicolumn{3}{|c|}{ Previous history of back pain } & \multicolumn{3}{|c|}{ Current back pain } & \multirow{2}{*}{$\frac{\text { Duration* }}{\text { p-value }}$} & \multirow{2}{*}{$\begin{array}{c}\text { VAS }^{\#} \\
\text { p-value }\end{array}$} \\
\hline & no & yes & p-value & no & yes & p-value & & \\
\hline $\begin{array}{l}\text { Age } \\
\quad \text { Mean } \pm \text { SD (Range) }\end{array}$ & $\begin{array}{l}30.39 \pm 9.18 \\
\quad(21 \sim 53)\end{array}$ & $\begin{array}{c}31.37 \pm 8.74 \\
(22 \sim 59)\end{array}$ & 0.5354 & $\begin{array}{l}31.43 \pm 8.94 \\
(21 \sim 59)\end{array}$ & $\begin{array}{c}30.97 \pm 8.70 \\
(22 \sim 54)\end{array}$ & 0.7056 & 0.7056 & $0.000^{* *}$ \\
\hline $\begin{array}{l}\text { Years at work } \\
\text { Mean } \pm \text { SD (Range) }\end{array}$ & $\begin{array}{c}6.04 \pm 6.57 \\
(0.3 \sim 32)\end{array}$ & $\begin{array}{l}7.61 \pm 6.80 \\
(0.25 \sim 28)\end{array}$ & 0.2032 & $\begin{array}{c}8.10 \pm 7.47 \\
(0.3 \sim 32)\end{array}$ & $\begin{array}{l}6.30 \pm 5.54 \\
(0.25 \sim 28)\end{array}$ & 0.0692 & 0.0692 & $0.001 * *$ \\
\hline $\begin{array}{l}\text { Doing administrative } \\
\text { tasks: odds ratio }\end{array}$ & $17 / 22=0.772$ & $48 / 130=0.369$ & $0.0454^{*}$ & $38 / 84=0.452$ & $27 / 67=0.403$ & 0.6998 & 0.7748 & 0.172 \\
\hline
\end{tabular}

Table 4. Factors Associated with the Six-Item Core Set Measure: p-value (number of respondents)*

\begin{tabular}{lccccccc}
\hline Outcome & $\begin{array}{c}\text { 1a. How } \\
\text { bothersome the bothersome the } \\
\text { back pain is }\end{array}$ & $\begin{array}{c}\text { 1b. How } \\
\text { leg pain is }\end{array}$ & $\begin{array}{c}\text { 2. How back } \\
\text { pain interferes } \\
\text { with normal } \\
\text { work }\end{array}$ & $\begin{array}{c}\text { 3. Satisfaction } \\
\text { on Back Pain }\end{array}$ & $\begin{array}{c}\text { 4. Days cutting } \\
\text { down on things } \\
\text { for more than } \\
\text { half a day }\end{array}$ & $\begin{array}{c}\text { 5. Days you } \\
\text { were kept from } \\
\text { going to work }\end{array}$ & $\begin{array}{c}\text { 6. Satisfaction } \\
\text { with overall } \\
\text { medical care }\end{array}$ \\
\hline Age & $0.0038^{* *}$ & $0.0330^{* *}$ & $0.0233^{* *}$ & 0.7444 & 0.0816 & 0.0940 & 0.8650 \\
$(\mathrm{n}=163)$ & $(\mathrm{n}=149)$ & $(\mathrm{n}=168)$ & $(\mathrm{n}=162)$ & $(\mathrm{n}=151)$ & $(\mathrm{n}=151)$ & $(\mathrm{n}=135)$ \\
Years at work & $0.0001^{* *}$ & $0.0319^{* *}$ & $0.0003^{* *}$ & 0.7582 & 0.3340 & 0.0709 & 0.5727 \\
& $(\mathrm{n}=148)$ & $(\mathrm{n}=135)$ & $(\mathrm{n}=153)$ & $(\mathrm{n}=147)$ & $(\mathrm{n}=140)$ & $(\mathrm{n}=140)$ & $(\mathrm{n}=121)$ \\
$\begin{array}{l}\text { Doing } \\
\text { administrative } \\
\text { tasks }\end{array}$ & 0.9001 & 0.0550 & 0.3796 & 0.5396 & 0.6190 & 0.1844 & 0.2411 \\
$(\mathrm{n}=163)$ & $(\mathrm{n}=153)$ & $(\mathrm{n}=173)$ & $(\mathrm{n}=167)$ & $(\mathrm{n}=155)$ & $(\mathrm{n}=155)$ & $(\mathrm{n}=139)$ \\
\hline
\end{tabular}

* The number of respondents varies across items because respondents did not respond to all items.

** $\mathrm{p}<0.05$ 
Table 5. Factors associated with willingness of attending a complimentary exercise program

\begin{tabular}{|c|c|c|}
\hline Factors & $\begin{array}{c}\text { Respondents* } \\
\text { (n) }\end{array}$ & P-value \\
\hline \multicolumn{3}{|l|}{ Among all respondents } \\
\hline Age & 217 & 0.2757 \\
\hline years at work as a nurse & 217 & 0.1323 \\
\hline doing administrative tasks at work & 217 & 0.4910 \\
\hline previous history of back pain & 217 & 0.6710 \\
\hline \multicolumn{3}{|c|}{ Among the respondents who reported a previous history of back pain } \\
\hline current back pain & 177 & $0.0280^{* *}$ \\
\hline duration of the most recent episode of back pain & 178 & 0.9297 \\
\hline VAS of the most recent episode of back pain & 178 & 0.2940 \\
\hline \multicolumn{3}{|l|}{ Six-Item Core Set } \\
\hline C1a. How bothersome back pain is & 168 & 0.0529 \\
\hline C1b. How bothersome leg pain is & 153 & 0.1018 \\
\hline C2. How back pain interferes with normal work & 173 & 0.4412 \\
\hline C3. Satisfaction on back pain & 167 & 0.1470 \\
\hline C4. Days cutting down on things for more than half a day & 155 & 0.0593 \\
\hline C5. Days you were kept from going to work & 155 & 0.3264 \\
\hline C6. Satisfaction with overall medical care & 139 & $0.0049 * *$ \\
\hline
\end{tabular}

* The number of respondents varies across items because respondents did not respond to all items.

$* * \mathrm{p}<0.05$.

\section{Factors associated with willingness}

\section{to attend exercise programs}

Table 5 presents the factors associated with willingness to attend a complimentary exercise program. The analysis demonstrated that current back pain and satisfaction with treatment were significantly associated with willingness to attend a complimentary exercise program. Those who reported current back pain and who were not satisfied with their treatment were more likely to be willing to attend a complimentary exercise program.

\section{DISCUSSION}

This cross-sectional study examined the point and lifetime prevalence of low back pain among hospital nurses in Taiwan. We also investigated the association between back pain characteristics and factors such as age, number of years at work, physical load, and the nature of the workplace. Back pain characteristics explored in our study included the previous history of back pain, current back pain, duration and severity of the most recent episode of back pain, and outcomes of back pain, as measured by the Six-Item Core Set questionnaire.

This cross-sectional study demonstrated high point prevalence $(43.78 \%)$ and lifetime prevalence $(82.03 \%)$ of low back pain in hospital nurses in Taiwan - a finding consistent with those of previous studies concerning nursing personnel in other countries [5,11-13]. The high point prevalence and lifetime prevalence of low back pain among hospital nurses in Taiwan emphasized the importance of the problem of back pain in nursing personnel in Taiwan hospitals. The study also examined the outcomes 
of back pain among Taiwan hospital nurses, as measured by the Six-Item Core Set. The Six-Item Core Set demonstrated that back pain or leg pain (sciatica) was considered bothersome by a large proportion of the respondents who reported the previous history of back pain.

In the present study, a univariate analysis demonstrated that both age and the number of years worked as a nurse were significantly associated with pain severity, the extent of bothersomeness of back/leg pain, and the extent to which back pain interfered with normal work. As age and number of years at work might confound each other, a multivariate analysis demonstrated that after the number of years at work was controlled for, age was not significantly associated with any characteristics or outcomes of back pain. Nurses who had worked for a longer period of time were more likely to have less severe pain. In addition, for these respondents, back or leg pain was less bothersome. Nurses who had worked for a longer period were also less likely to report that back pain interfered with their normal work. Our finding that the number of years at work was significantly associated with pain severity and outcomes of back pain is consistent with certain previous studies [13].

Our study divided the respondents into two groups (nurses doing clinical tasks vs. nurses doing administrative tasks) to investigate the importance of physical load. We assumed that those who worked in a ward (doing clinical tasks) had a heavier physical load than those who performed administrative tasks. The study demonstrated that doing administrative or clinical tasks was not significantly associated with a current or previous history of back pain. Neither was it associated with pain severity or the outcomes of back pain. The previous studies with regard to whether physical load is a risk factor for back pain in hospital nurses presented mixed results. Several studies identified physical load to be a risk factor of low back pain in hospital nurses [11]. A recent systematic review has found no significant causal association between workplace manual handling and low back pain [14].
This study also examined the importance of the nature of workplaces for Taiwan hospital nurses. Our data did not show any significant differences in pain characteristics or the outcome of back pain between those who worked in an intensive care unit and those who did not. This finding contradicts some previous studies indicating that nurses working in an intensive care unit are at a higher risk of developing back pain [15].

In our study, almost ninety percent $(87.74 \%)$ of the respondents reported that back pain did not prevent them from going to work. We also demonstrated that sick leave is not significantly associated with age, number of years at work, performing administrative tasks, or any pain characteristics. This finding contradicts those of previous studies in western countries that identified back pain to be an important cause of sick leave. In our study, some respondents reported that they were not allowed by their supervisors to be absent from work even when suffering from back pain because there were not enough substitute nurses. Inability to take sick leave may aggravate back pain in nurses. Furthermore, asking nurses with acute back pain to work may lead to medical errors and lower the quality of their care. Some respondents also reported that they did not receive any medical care for their back pain due to lack of time. When offered a free back exercise program, a large proportion of the respondents to our questionnaire (63.07\%) reported that they did not have time to take part in it. Lack of time to seek medical care may aggravate back pain in hospital nurses and influence the quality of medical care. It is noteworthy that more than a half of our study population $(57.14 \%)$ was less than 30 years old and more than $80 \%$ of our study population was less than 40 years old. More than a half of our respondents had been working as nurses for less than 5 years. Our study demonstrated that experienced nurses felt less severe back pain and had better outcomes of back pain compared to inexperienced nurses. This finding might imply that nurses with back pain are more likely to leave their jobs at the hospital, which 
has been reported in the literature [7]. A lack of experienced nurses may also adversely affect the quality of care at a hospital.

One of the limitations of this study is that it is a one-site study. In addition, although our study did not exclude male respondents, there were no male nurses employed in Keelung Hospital during the study period. There are very few male nurses in Taiwan. Our study was also limited by its exclusion of nurses working in the operating room because literature demonstrated that those who work in the operating room exhibit a distinct pattern of musculoskeletal pain [16]. Therefore, the association between gender or working in the operating room and low back pain could not be investigated in our study. Finally, we used a division based on the fact whether a nurse was doing administrative or clinical tasks as a measure of physical load, which might have led to some degree of measurement error.

\section{CONCLUSION}

Our study demonstrated that back pain is common among hospital nurses in Taiwan. Among the demographic characteristics and work-related factors investigated in our study, number of years worked as a nurse was identified as an important risk factor for pain characteristics and outcomes of back pain in hospital nurses in Taiwan.

\section{REFERENCES}

1. Andersson GB. Epidemiological features of chronic low-back pain. Lancet 1999;354(9178):581-5.

2. National Institute for Occupational Safety and Health. Program of the National Institute for Occupational Safety and Health, FY 1985 [program plan]. Atlanta (GA): NIOSH; 1985.

3. Hofmann F, Stossel U, Michaelis M, Nubling M, Siegel A. Low back pain and lumbago-sciatica in nurses and a reference group of clerks: results of a comparative prevalence study in Germany. Int Arch Occup Environ Health 2002;75(7):484-90.
4. Dawson AP, McLennan SN, Schiller SD, Jull GA, Hodges PW, Stewart S. Interventions to prevent back pain and back injury in nurses: a systematic review. Occup Environ Med 2007;64(10):642-50.

5. Edlich RF, Woodard CR, Haines MJ. Disabling back injuries in nursing personnel. J Emerg Nurs 2001;27(2):150-5.

6. Cohen-Mansfield J, Culpepper WJ 2nd, Carter P. Nursing staff back injuries: prevalence and cost in long term care facilities. Off J Am Assoc Ocuup Health Nurs 1996;44(1):9-17.

7. Fochsen G, Josephson M, Hagberg M, Toomingas A, Lagerstrom M. Predictors of leaving nursing care: a longitudinal study among Swedish nursing personnel. Occup Environ Med 2006;63(3):198-201.

8. Sherehiy BK, Karwowski W, Marek T. Relationship between risk factors and musculoskeletal disorders in the nursing profession: A systematic review. Occup Ergonom 2004;4(4):241-79.

9. Deyo RA, Battie M, Beurskens AJ, Bombardier C, Croft P, Koes B, et al. Outcome measures for low back pain research. A proposal for standardized use. Spine (Phila Pa 1976). 1998;23(18):2003-13.

10. Lee LH, Lue Y-J, Yen AM-F, Chen TH-H, Hsieh LL-C. Chinese Version of the Standardized Outcome Measures for Low Back Pain and a Pilot Study. Formos J Phys Ther 2006;31(4):237-245.

11. Sikiru L, Hanifa S. Prevalence and risk factors of low back pain among nurses in a typical Nigerian hospital. Afr Health Sci 2010;10(1):26-30.

12. Mitchell T, O'Sullivan PB, Burnett AF, Straker L, Rudd C. Low back pain characteristics from undergraduate student to working nurse in Australia: a cross-sectional survey. Int J Nurs Stud 2008;45(11):1636-44.

13. Smith DR, Mihashi M, Adachi Y, Koga H, Ishitake T. $A$ detailed analysis of musculoskeletal disorder risk factors among Japanese nurses. J Safety Res 2006;37(2):195-200.

14. Roffey DM, Wai EK, Bishop P, Kwon BK, Dagenais S. Causal assessment of workplace manual handling or assisting patients and low back pain: results of a systematic review. Spine 2010;10(7):639-51. 
15. June KJ, Cho SH. Low back pain and work-related factors among nurses in intensive care units. J Clin Nurs 2011;20 (3-4):479-87.

16. Bos E, Krol B, van der Star L, Groothoff J. Risk factors and musculoskeletal complaints in non-specialized nurses, IC nurses, operation room nurses, and X-ray technologists. Int Arch Occup Environ Health 2007;80(3):198-206.

This work is available in Open Access model and licensed under a Creative Commons Attribution-NonCommercial 3.0 Poland License - http://creativecommons.org/ licenses/by-nc/3.0/pl/deed.en. 